\title{
Erudite Primer to the Constitutional Practice of Deliberative Democracy*
}

\author{
by Ron Levy \\ Australian National University College of Law, Australia
}

(Mendes, Conrado Hubner. Constitutional Courts and Deliberative Democracy. Oxford: Oxford University Press, 2013)

$\mathrm{M}$ endes's book offers a wide-ranging primer or literature review of constitutional aspects of what may be called the law of deliberative democracy (Levy, 2013). This cross-over field of scholarship unites deliberative and legal theory.

It should be no surprise that academic interest in this new field is on the rise. The deliberative democratic turn in political theory has often been called a key development in the study of democracy. Yet though deliberative theory makes many assumptions about the functioning of courts in a deliberative democracy, until recently only a few scholars with relevant legal expertise had undertaken to test and improve these assumptions. Mendes, a Brazilian professor of law, has staked out (alongside a few others, including Christopher Zurn and the late Carlos Santiago Nino) a set of intriguing questions about deliberative democracy in relation to constitutional theory. The strength of the book is in its detailed examination of what still largely remains at least from the perspective of deliberative theory a black box: the internal processes of constitutional courts.

This kind of scholarship is overdue. Deliberative theory grew up alongside certain strands of legal scholarship with which it seldom expressly intersects, but with which it has clear affinities. These include the rule of law, alternative dispute 
resolution, normative jurisprudence, the politics/election law, and theories of judicial decision-making. Though it came of age only in the past few decades, deliberative democracy theory has antecedents in, for example, Burke, Mill, Socrates, and many others. Modern deliberative theory is novel principally for the density and sophistication of its analyses. But can its modern analytic approaches and categories shed light on basic questions of legal theory, and vice versa?

Mendes's book identifies a number of live and fascinating questions. One of his aims is to move beyond established theories of judicial review implicating deliberation at a broad level and instead to view courts as deliberators in finergrained detail. For instance, dialogue theories justify judicial review under a constitution by picturing not a hierarchy but a conversation between branches of government. Hence, in place of a simple model of judicial supremacy, the theory imagines a horizontal partnership between courts and the elected branches in which each brings a unique institutional capability to the discussion. Some have pictured this complementarity in deliberative terms: the courts being the more clearly deliberative partner. But Mendes, spotting an opening in the literature, asks how exactly the courts serve their deliberative function. That is, not only does he wonder whether the products of judicial decision-making aid in dialogue but also exactly how judges themselves deliberate.

Mendes also looks beyond broad assumptions about the courts' deliberative roles as, for example, catalysts of public debate. His more particular question is whether constitutional courts, in fact, deliberate well. For example, does the collegiate nature of many such courts prime them to do so? He does not give a simple answer to this (nor indeed to any of his own queries). Mendes is more of a systematizer and presenter of taxonomies than a purveyor of simple answers. His language waxes metaphorical, even sometimes lyrical. He offers a set of nuanced, layered suggestions. Among these are numerous nuggets suggesting, often in precisely enumerated detail, intriguing reasons for (and sometimes against) the proposition that their roles as deliberators justifies constitutional judges' outsized institutional power.

The book is not for the casual reader. It assumes some background in deliberative theory, and ideally in legal theory as well. However, especially from the middle portions of the book onward, Mendes's assorted taxonomies and cross- 
cutting insights make the reading worthwhile. By asking the questions he does, Mendes encourages us to probe the roles and possibilities of deliberation on multimember courts. How such courts deliberate has long been of interest to legal researchers, and especially those with an interest in judicial decision-making. However, we have not often previously seen comparisons of how judicial deliberation is understood in the separate camps of legal and deliberative theory. Mendes's book arrives at a time when a growing number of scholars are interested in precisely these sorts of questions. It is a welcome addition to the literature, apprised of the wide canons of both deliberative and legal theory and well able to bridge the two.

Revised by Cabo Verde

\section{References}

LEVY, R. (2013), The Law of Deliberative Democracy: Seeding the Field. Election Law Journal. Vol. 12, № 4, pp. 355-371.

NINO, Carlos Santiago (1996), The Constitution of Deliberative Democracy. New Haven: Yale University Press.

ZURN, Christopher F. (2007), Deliberative Democracy and the Institutions of Judicial Review. Cambridge: Cambridge University Press. 